\title{
Arctic Cryosphere: Changes and Impacts
}

\author{
T. V. Callaghan, M. Johansson, T. D. Prowse, \\ M. S. Olsen, L.-O. Reiersen
}

\begin{abstract}
The Arctic cryosphere is a critically important component of the earth system, affecting the earth's energy balance, sea level, greenhouse gases and atmospheric circulation, transport of heat through ocean circulation, ecology and human resource use and well-being. The Arctic cryosphere is, however, changing rapidly with multiple important consequences that will potentially affect the earth system including the human population. The drivers of changes in the Arctic's cryosphere, the recent and projected changes in the cryosphere and the consequences for future climate warming, sea level rise, ecology and human wellbeing, have been comprehensively assessed by the Arctic Council's Snow Water, Ice, and Permafrost in the Arctic (SWIPA) Project through its Arctic Monitoring and Assessment Programme Working Group. This article introduces the assessment and the associated papers within a special issue of the journal Ambio that extract and present some of the major findings of the SWIPA report.
\end{abstract}

Keywords Snow - Water - Ice - Permafrost - Arctic . Climate feedbacks - Ecology - Atmospheric circulation . Ocean circulation $\cdot$ Societies $\cdot$ Cultures $\cdot$ Peoples

\section{INTRODUCTION}

The Arctic cryosphere is a critically important component of the earth system. It affects the energy balance of the earth, resulting in a net cooling; its dynamic processes affect air and ocean circulation at a global scale; it stores freshwater from seasonal to millennial time scales and thereby regulates the availability of freshwater during the main growth season, and it affects sea level and thus the extent and shape of the earth's land masses, which determines the surface available for human habitation. Furthermore, the Arctic's cryosphere stores or regulates the release of large quantities of greenhouse gases such as methane and carbon dioxide. As the Arctic's cryosphere is experiencing dramatic change due to global warming, it has been the subject of extensive and recent research and assessment.

In 2005, the Arctic Council (www.arctic-council.org) published the comprehensive report "Arctic Climate Impact Assessment" (ACIA) (ACIA 2005) which drew global scientific and political attention to the effects of climate change in the Arctic. Observations of further cryospheric change in the first decade of the twenty-first century that often exceeded the rates of change predicted by ACIA (2005), spurred the Arctic Council to launch a follow up to the ACIA: the "Snow, Water, Ice, and Permafrost in the Arctic" (SWIPA, www.amap.no/swipa) project, the results of which were published in 2011 (AMAP 2011).

The SWIPA assessment builds on peer reviewed literature and has involved approximately 200 scientists and experts. Using the ACIA as the benchmark the SWIPA work synthesized observations and research on recent changes in and across the components of the Arctic Cryosphere and discussed potential effects of changes in a local, regional and global perspective. In its first stages, the project liaised with the International Polar Year (IPY, www.ipy.org) project office and national IPY contacts in order to ensure representation of major relevant IPY projects in the SWIPA assessment. Furthermore, the Arctic Council working group Arctic Monitoring and Assessment Programme (AMAP, www.amap.no) that was requested to carry out the assessment partnered with the International Arctic Science Committee (http://iasc.arcticportal.org), the World Climate Research Programme's Climate and Cryosphere Project, http://clic.npolar.no) and the International Arctic Social Sciences Association (www.iassa.org) to complete the task. 
The SWIPA report (AMAP 2011) is very comprehensive, containing about 542 pages and 12 chapters. The chapters include an introduction to the SWIPA process, chapters on the main climatic drivers of changes in the cryosphere, specific components of the cryosphere (lake and river ice, permafrost, sea ice, snow, small mountain glaciers and ice caps, and the Greenland ice sheet) together with synthesis chapters that bring together consequences of changes in the major cryospheric components for feedbacks to the climate system, sea level, ecology and Arctic societies, cultures and peoples. A final overview chapter sets all this information within the context of progressive interactions over time and space between the changes in cryospheric components and their multiple consequences (AMAP 2011).

\section{GOALS OF THE CURRENT STUDY}

The main goals of the current Ambio special issue (Callaghan et al. 2011a [this issue]) are to

(a) summarise some of the extensive key SWIPA chapters.

(b) make this information more widely available to a global audience with multi-disciplinary interests.

We achieve these goals through the identification and focusing on key material from many of the SWIPA chapters by the original lead authors. As the SWIPA chapters were comprehensively reviewed with documented and approved revisions (available from www.amap.no), the authors have ensured that factual material and interpretations are consistent between these original chapters and the condensed separate manuscripts that comprise this special issue. Furthermore, the SWIPA findings have been made more accessible by publishing in the widely distributed journal "Ambio" which is "A Journal of the Human Environment".

\section{STRUCTURE}

This special issue of Ambio presents papers that assess: recently observed changes in Arctic Climate that drive and interact with the Arctic's cryosphere (Walsh et al. 2011), recent, on-going and projected changes in snow (Callaghan et al. 2011b, c) and river and lake ice (Prowse et al. 2011a, $\mathrm{b}, \mathrm{c})$, and the consequences of these cryospheric changes for feedbacks to the climate system (Callaghan et al. 2011d), ecology of the Arctic (Vincent et al. 2011), and societies, cultures and peoples (Hovelsrud et al. 2011). A final paper synthesizes the results of all these papers and places them within the context of the entire SWIPA assessment (Olsen et al. 2011).
Acknowledgments We thank all the participants in the SWIPA process for contributing to the completion of a comprehensive assessment of the changing Arctic cryosphere, its climatic drivers and multiple consequences. We are particularly grateful to them and the leadership of the SWIPA process for making the SWIPA results available for this Ambio special issue. Numerous national funding agencies supported the SWIPA process and we are grateful for this support. We are grateful for financial contributions to the SWIPA production from Canada, Denmark, Norway and the Nordic Council of Ministers. We are particularly grateful to the Swedish Environmental Protection Agency (grant number 08/210) and the Swedish Research Council FORMAS (grant number 204-2009-45) for the grants to TVC and MJ for the publication of this special issue, to Environment Canada for a further grant to TDP to complete the financing of the publication, and finally to Professor F. Wrona for facilitating this.

\section{REFERENCES}

ACIA. 2005. Arctic climate impact assessment. 1042 pp. Cambridge: Cambridge University Press.

AMAP. 2011. Snow, water, ice and permafrost in the Arctic (SWIPA). Oslo: Arctic Monitoring and Assessment Programme (AMAP).

Callaghan, T.V., M. Johansson, and T.D. Prowse eds. 2011a. Arctic cryosphere: Changes and impacts, ed. T.V. Callaghan, M. Johansson, and T.D. Prowse. Ambio 40(S1). doi:10.1007/ s13280-011-0210-0.

Callaghan, T.V., M. Johansson, R.D. Brown, P.Y. Groisman, N. Labba, V. Radionov, R.G. Barry, O.N. Bulygina et al. 2011b. The changing face of Arctic snow cover: a synthesis of observed and projected changes. In Arctic cryosphere-Changes and impacts, ed. T.V. Callaghan, M. Johansson, and T.D. Prowse. Ambio 40(S1). doi:10.1007/s13280-011-0212-y.

Callaghan, T.V., M. Johansson, R.D. Brown, P.Y Groisman, N. Labba, V. Radionov, R.S. Bradley, S. Blangy et al. 2011c. Multiple effects of changes in Arctic snow cover. In Arctic cryosphere-Changes and impacts, ed. T.V. Callaghan, M. Johansson, and T.D. Prowse. Ambio 40(S1). doi:10.1007/ s13280-011-0213-X.

Callaghan, T.V., M. Johansson, J. Key, T.D. Prowse, M. Ananicheva, and A. Klepikov. 2011d. Feedbacks and Interactions: From the Arctic cryosphere to the climate system. In Arctic cryosphereChanges and impacts, ed. T.V. Callaghan, M. Johansson, and T.D. Prowse. Ambio 40(S1). doi:10.1007/s13280-011-0215-8.

Hovelsrud, G.K., B. Poppel, B. van Oort, J.D. Reist, J.L. White, H. Dannevig, S. Rybråten, D. Armitage et al. 2011. Arctic societies, cultures, and peoples in a changing cryosphere. In Arctic cryosphere-Changes and impacts, ed. T.V. Callaghan, M. Johansson, and T.D. Prowse. Ambio 40(S1). doi:10.1007/ s13280-011-0219-4.

Olsen, M.S., T.V. Callaghan, J.D. Reist, L.O. Reiersen, D. DahlJensen, M.A. Granskog, B. Goodison, G.K. Hovelsrud et al. 2011. The changing arctic cryosphere and likely consequences: an overview. In Arctic cryosphere-Changes and impacts, ed. T.V. Callaghan, M. Johansson, and T.D. Prowse. Ambio 40(S1). doi:10.1007/s13280-011-0220-y.

Prowse, T.D., K. Alfredsen, S. Beltaos, B.R. Bonsal, C. Duguay, A. Korhola, J. McNamara, W.F. Vincent, et al. 2011a. Arctic freshwater ice and its climatic role. In Arctic cryosphereChanges and impacts, ed. T.V. Callaghan, M. Johansson, and T.D. Prowse. Ambio 40(S1). doi:10.1007/s13280-011-0214-9.

Prowse, T.D., K. Alfredsen, S. Beltaos, B.R. Bonsal, C. Duguay, A. Korhola, J. McNamara, R. Pienitz, et al. 2011b. Past and future changes in Arctic lake and river ice. In Arctic cryosphere- 
Changes and impacts, ed. T.V. Callaghan, M. Johansson, and T.D. Prowse. Ambio 40(S1). doi:10.1007/s13280-011-0216-7.

Prowse, T.D., K. Alfredsen, S. Beltaos, B. Bonsal, W.B. Bowden, C. Duguay, A. Korhola, J. McNamara, et al. 2011c. Effects of changes in arctic lake and river ice. In Arctic cryosphereChanges and impacts, ed. T.V. Callaghan, M. Johansson, and T.D. Prowse. Ambio 40(S1). doi:10.1007/s13280-011-0217-6.

Vincent, W.F., T.V. Callaghan, D. Dahl-Jensen, M. Johansson, K.M. Kovacs, C. Michel, T.D. Prowse, J.D. Reist, et al. 2011. Ecological implications of changes in the arctic cryosphere. In Arctic cryosphere-Changes and impacts, ed. T.V. Callaghan, M. Johansson, and T.D. Prowse. Ambio 40(S1). doi:10.1007/ s13280-011-0218-5.

Walsh, J.E., J.E. Overland, P.Y. Groisman, and B. Rudolf. 2011. Ongoing climate change in the Arctic. In Arctic cryosphereChanges and impacts, ed. T.V. Callaghan, M. Johansson, and T.D. Prowse. Ambio 40(S1). doi:10.1007/s13280-011-0211-z.

\section{AUTHOR BIOGRAPHIES}

T. V. Callaghan $(\varangle)$ is a distinguished research professor at the Royal Swedish Academy of Sciences and professor of arctic ecology at the Universities of Sheffield, UK and Lund, Sweden. He specializes in arctic ecology, and climate and UV-B radiation impacts on arctic ecosystems.

Address: Royal Swedish Academy of Sciences, 10405 Stockholm, Sweden.

e-mail: terry_callaghan@btinternet.com

M. Johansson is a researcher at the Department of Earth and Ecosystem Sciences, Lund University and at the Royal Swedish Academy of Sciences, Stockholm, Sweden. She specializes in permafrost dynamics in relation to climate change and its impact on ecosystems. Address: Dept. of Earth and Ecosystem Sciences, Division of Physical Geography and Ecosystem Analyses, Lund University, Sölvegatan 12, 22362 Lund, Sweden.

e-mail: margareta.johansson@nateko.lu.se
T. D. Prowse is a senior research scientist with Environment Canada and a professor in the Department of Geography at the University of Victoria. His research focuses on the effects of climate variability and change on cold-regions hydrology, hydro-climatology, and hydroecology.

Address: Environment Canada, Department of Geography, University of Victoria, Victoria, B.C V8P 5C2, Canada.

e-mail: terry.prowse@ec.gc.ca

M. S. Olsen is programme coordinator of the Danish Arctic Climate Support Fund (Danish Ministry of Climate and Energy) which supports climate change effects monitoring programmes primarily in Greenland. Since 2009, Mr. Olsen has served as vice-chair of the Arctic Monitoring and Assessment Programme Working Group and he has been chairing the SWIPA Integration Team.

Address: Danish Energy Agency, Amaliegade 44, 1256 Copenhagen, Denmark.

e-mail:mso@ens.dk

L.-O. Reiersen is executive secretary for Arctic Monitoring and Assessment Programme (AMAP). He has for the last 20 years been planning and implementing significant Arctic monitoring and assessment programmes covering trends and effects of pollutants and climate change on Arctic ecosystems and humans.

Address: AMAP, P.O. Box. 8100 Dep., 0032 Oslo, Norway.

e-mail: lars-otto.reiersen@amap.no 